Iran Journal of Nursing (IJN)

Vol 34, No. 130, Jun 2021: 48- 58

\title{
The Correlation Between Perceived Organizational Support and Quality of Work Life in the Operational Staff of Tehran Medical Emergency Center,
} 2019

\author{
Erfan Yarmohammadinejad ${ }^{1}$, Mahnaz SeyedoShohadaee ${ }^{2}$, Peyman Saberian ${ }^{3}$, \\ Hamid Haghani ${ }^{4}$, Fereydoon Khayeri ${ }^{5}$
}

\begin{abstract}
Background \& Aims: Given the importance and role of the organization's human resources, focusing and addressing issues such as the quality of work life that lead to increased employee performance, reduced absenteeism and leave of duty is important. Quality of work life is a set of organizational conditions and is created when the management of the organization is democratic, staff are treated with respect, and a safe work environment is provided. In other words, improving the quality of work life in staff is one of the important factors to ensure the sustainability of the health system. Considering the sensitive and stressful job situation of emergency center staff and the contradictory results of researches conducted on the quality of life of staff, the present study aimed to analyze the relationship between perceived organizational support and quality of work life of the operational staff of Tehran emergency centers.

Materials \& Methods: This descriptive, cross-sectional, correlational study was conducted on the operational staff of Tehran Emergency Center in the second six months of 2019. The sampling method was multi-stage stratified with the proportional allocation and 200 qualified staff from the six emergency centers of Tehran (north, south, east, west, center, Islamshahr) were included in the study. Inclusion criteria were having a diploma and higher degrees and having at least six months of experience as operational staff. Demographic information form, quality of work life questionnaire developed by Walton, and Eisenberg perceived organizational support questionnaire were used for data collection. The researcher returned 24-48 hours after the distribution of the questionnaires and collected the completed questionnaires. Then, the data were analyzed using independent $t$-test, ANOVA, Pearson's correlation-coefficient, and Kruskal-Wallis tests in SPSS version 16.

Results: The results of the current study revealed that $42.2 \%$ and $41.1 \&$ of staff considered their income to be insufficient and somewhat sufficient respectively and the average work experience of the surveyed staff was 10.68 \pm 6 . The quality of work-life of staff of medical emergency center of Tehran was $96.1 \pm 22$ which was moderate. The quality of work life in the dimension of social integration in the job with an average of $3.09 \pm 0.97$ was the highest and in the dimension of the role of work life with an average of $2.35 \pm 0.87$ was the lowest among other

1. Department of Emergency of Nursing, School of Nursing and Midwifery, Iran University of Medical Sciences, Tehran, Iran

2. Department of Medical -Surgical Nursing, School of Nursing and Midwifery, Iran University of Medical Sciences, Tehran, Iran

3. Department of Anesthesiology, School of Medicine, Imam Khomeini Hospital, Tehran University of Medical Sciences, Tehran, Iran

4. Department of Biostatistics, School of Health, Iran University of Medical Sciences, Tehran, Iran

5 . Department of Medical -Surgical Nursing, School of Nursing and Midwifery, Iran University of Medical Sciences, Tehran, Iran


dimensions. Besides, the organizational support average was $82.2 \pm 0.152$ which was at the intermediate level and the average score of organizational support was $28.49 \pm 5.06$. Finally, there was no significant relationship between the quality of work-life and its dimensions with perceived organizational support. The results of the correlation between these variables and demographic characteristics of staff of emergency center showed a statistically significant relationship between that the quality of work life with education $(\mathrm{P}=0.013)$. The average score of staff with diploma was significantly lower than staff with associate degree $(\mathrm{P}=0.026)$, bachelor degree $(\mathrm{P}=0.002)$, and master degree $(\mathrm{P}=0.016)$, and the difference was not significant in other cases. Another variable that had a statistically significant relationship with the quality of work life was employment status $(\mathrm{P}=0.015)$. The average score of staff with casual employment was significantly lower than corporate $(\mathrm{P}=0.041)$ and formal staff $(\mathrm{P}=0.006)$. Moreover, perceived organizational support had no statistically significant relationship with any of the individual and job variables of the staff. The average score of staff with casual employment was significantly lower than those with corporate $(\mathrm{P}=0.041)$ and formal employment $(\mathrm{P}=0.006)$. Perceived organizational support also had no statistically significant relationship with individual and job variables of the staff.

Conclusion: According to the results of the study on the average perceived organizational support and quality of work life, organizational efforts of managers and related officials should be directed towards optimizing the organizational support and quality of work life of this group of staff. It is important to pay attention to these two concepts in the pre-hospital emergency operation staff because it can affect the professional, personal, life, and social aspects of their life. Considering that this study was conducted in Tehran Emergency Center, it is suggested that similar researches be conducted in other medical centers of other cities and on other clinical professions to compare the results.

Keywords: Quality of Work-life, Perceived Organizational Support, Pre-hospital Emergency

\section{Conflict of Interest: No}

How to Cite: Yarmohammadinejad E, SeyedoShohadaee M, Saberian P, Haghani H, Khayeri F. The Correlation Between Perceived Organizational Support and Quality of Work Life in the Operational Staff of Tehran Medical Emergency Center, 2019. Iran Journal of Nursing. 2021; 34(130):48-58.

Received: 13 March 2021

Accepted: 14 Jun 2021 


\section{حمايت سازمانى ادراك شده و كيفيت زندكى كارى كار كنان عملياتى مركز اورخانس تهران در

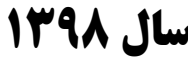

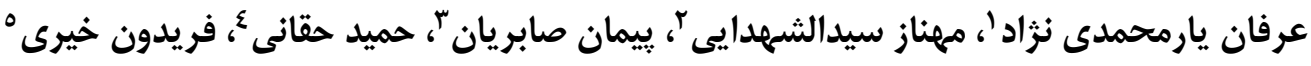

جكيده

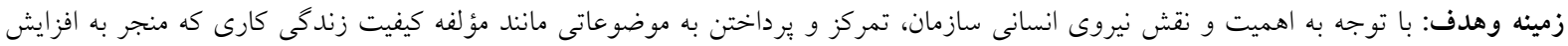

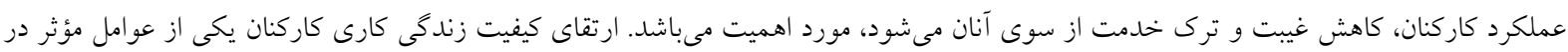

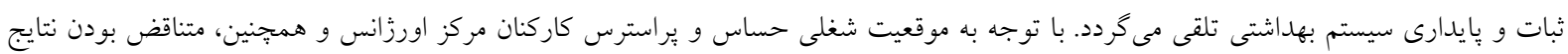

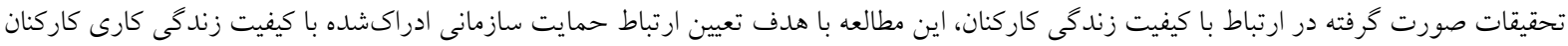
عملياتى مراكز اورزانس تهران انجام شد. روش بررسى: اين مطالعهى مقطعى از نوع توصيفى همبستكى بر روى كاركنان عملياتى مركز اورزانس تهران در شش ماهه دوم سال 19با (شش ماهه

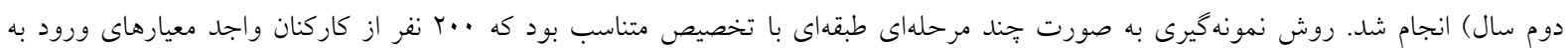

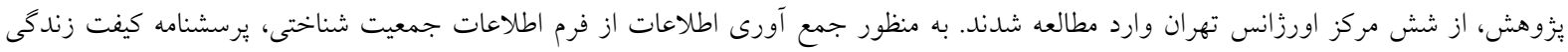

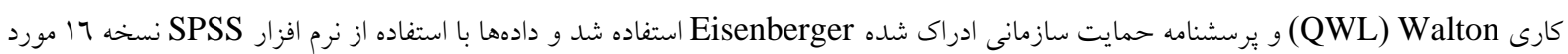
تجزيه تحليل قرار كرفت.

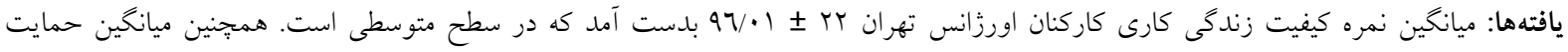
سازمانى كاركنان مورد يزوهش

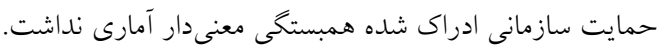

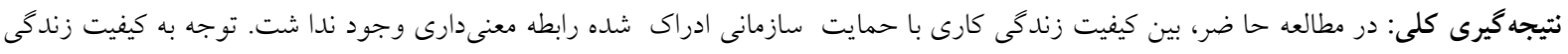

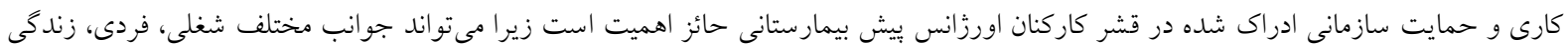
و اجتماعى آنها را تحت تأثير قرار دهد.

كليل وازهها: كيفيت زندگى كارى، حمايت سازمانى ادراك شده، اورزانس بيش بيمارستانى تعارض منافع: وجود ندارد. تاريخ دريافت: س

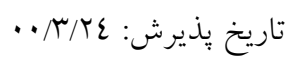

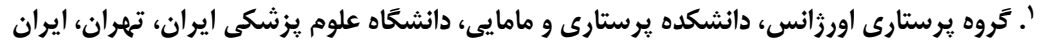

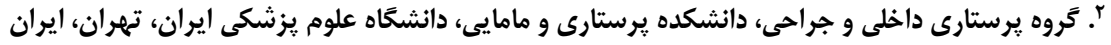

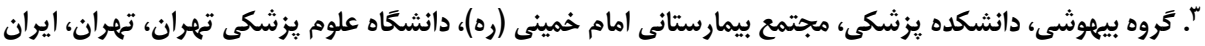

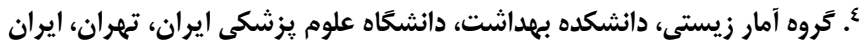

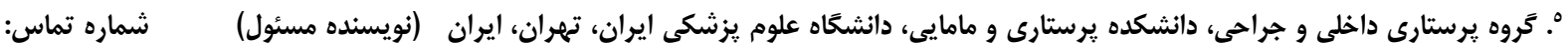
Email: Khayeri.f@iums.ac.ir

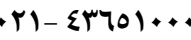


يكى از مفاهيم مورد توجه در سـازمان و نيروى انسـانى،

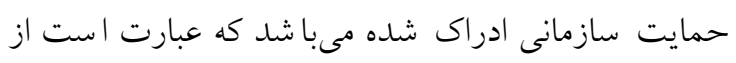

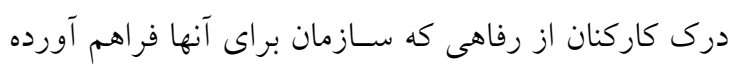
است (9). كاركنانى كه حمايت سازمانى را درك مى كنند نه

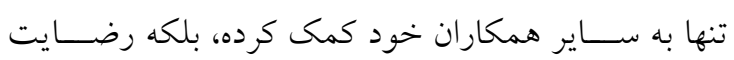
شغلى بالاتر، مشاركت شغلى بيشتر و غيبت شغلى كمترى

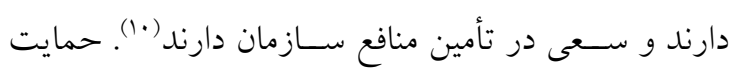
سازمانى ادراى شده موجبات افزايش بهرهورى، عملكرد

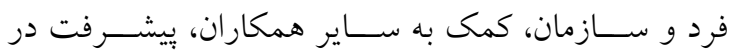

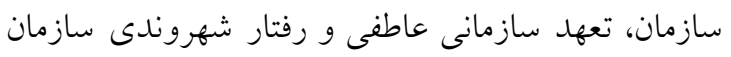

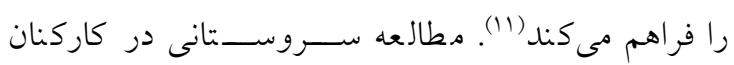

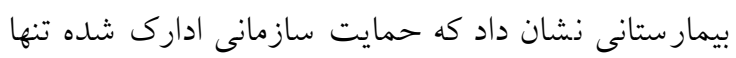
با برخى از مؤل لفه هاى عملكرد كارى ارتباط معنى دار

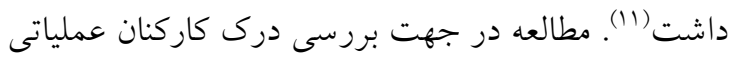
اورزانس در زمينه حمايت سازمانى يافت نشد.

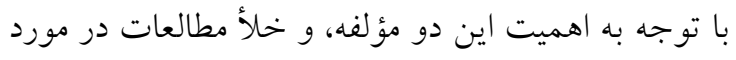

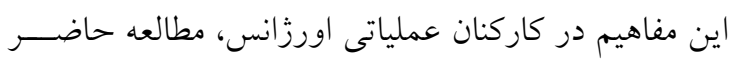

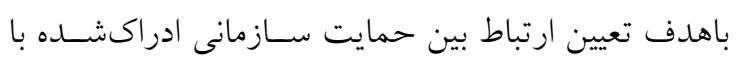

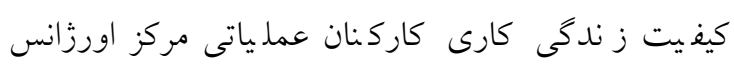

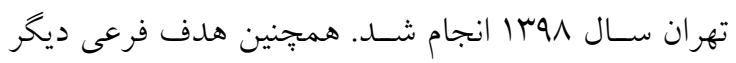
در اين يزوهش تعيين ارتباط دو مفهوم مورد سنجش بود.

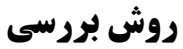
اين مطالعهى مقطعى از نوع توصيفى همبستخى بود. نمونه

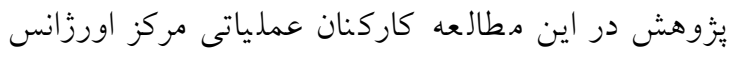

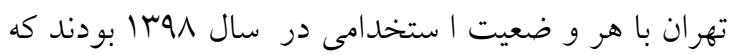

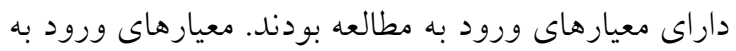
مطالعه شــامل داشــن مدرك دييلم (جهت امدادكران و تكنسينها) و بالاتر (دكترى، كار شناسى ارشد، كار شناس

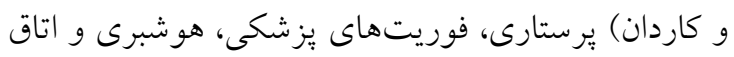
عمل و داشـتن حداقل شـش ماه سـابقه به عنوان كاركنان عملياتى بود. براى تعيين حجم نمونه در سطح اطمينان 90

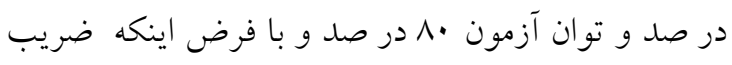
همبسـتخى بين كيفيت زندكى كارى كاركنان با هر يكى از
مقلدمه

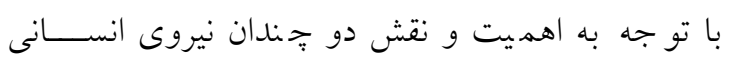

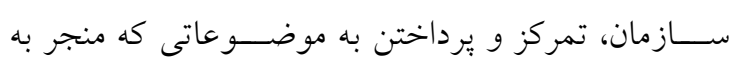
افزايش عملكرد كاركنان، كاهش غيبت و ترك خدمت از سـوى آنان مىشـود مانند مؤلفه كيفيت زندگى كارى مهم است (1). حيطه بيش بيمار ستانى با فضاى نايايدار، بيماران نـامشــخص ازنظر عفونى و كمبود نيروهـاى عمليـاتى

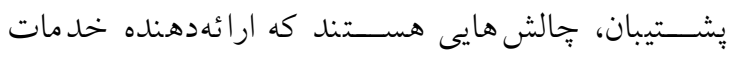
اورزانس (EMS) هرروزه با آن روبرو هستند (r). كاركنان اورزانس بيش بيمارستانى علاوه بر مشكالات روانشناختى

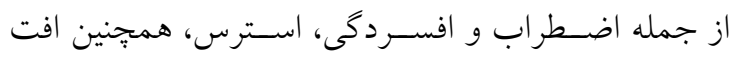
كيفيت زندكى و عملكرد ضــيف كارى در اورزانس را تجربيه مى كنند (r) كيفيت زندكى كارى، مجموعهاى از شـــرايط ســازمانى و زمانى بوجود مى آيد كه مديريت سازمان دموكراتيك باشد، با كاركنان با احترام رفتار شـود و محيط كارى امنى فراهم كردد كه ساير مشخصههاى آن عبارتند از سطح رضايت كارى، انخيزش، دركيرى و تعهد افراد به كار (ع). كيفيت زندگى كارى بهعنوان عامل كليدى تعيين كننده بِيامدهاى

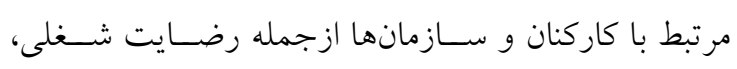
تعهد ســـازمانى، كاهش ترى خدمت كاركنان و تمايل كاركنان به مشاركت در جهت سودآورى سازمان در نظر كرفته مى شـــود (0) و از اهميت بســز ايى براى نظام هاى سـلامت و ارائهدهند گان مراقبت هاى بهداشـتى و درمانى

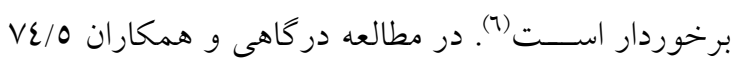
در صد ير ستاران شاغل در 10 بيمار ستان داذشخاه علوم

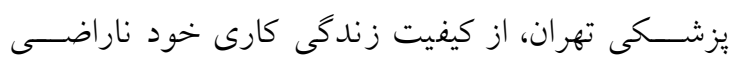

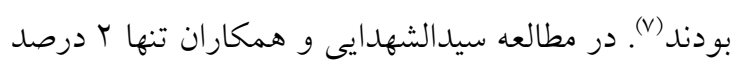
از ير ستاران كيفيت زندگى كارى شان را در سطح مطلوب

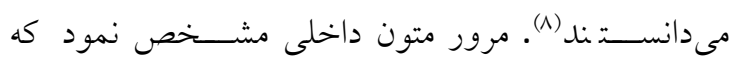
مطالعهاى كه به بررســى كيفيت زندگى كارى در كاركنان عملياتى اورزانس بيش بيمارســانى برداخته باشـــ يافت 
زندگى كارى بالاتر است. جهت سنجش حمايت سازمانى ادراك شــده از برسـشــــامه مرتبط در اين زمينه اسـتفاده كرديد كه تو سط Eisenberger و همكارانش تهيه شده

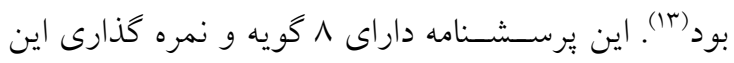
"يرسـشــنامه V V امتيازى بود كه براى گزينه هاى (ا كاملاً مخالفم)، (انســـبتاً مخالفم)"، (اكمى مخالفم)"، (انظرى ندارم)"،

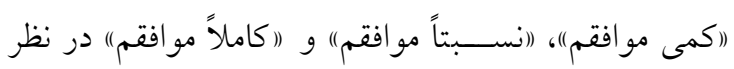

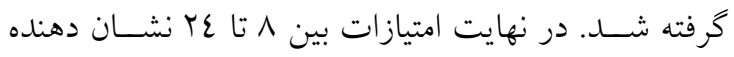
حمايت سازمانى ادراك شده ضعيف، بين عَ تا •ع نشان دهنده حمايت سازمانى ادراك شده متو سط، امتيازات بين

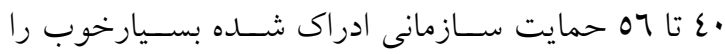

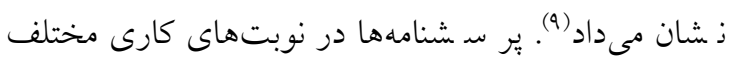

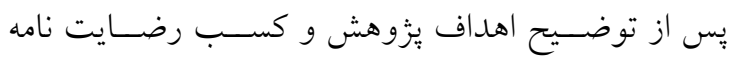

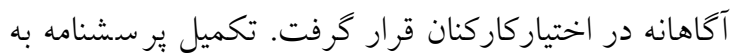

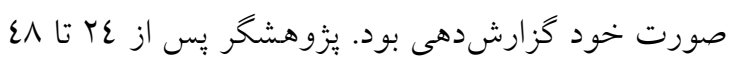

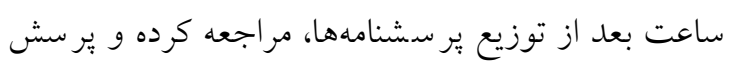

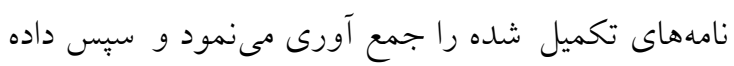

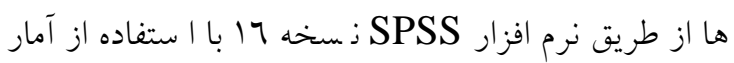
توصيفى در قالب جدول و شاخصهاى عددى برى به توصيف

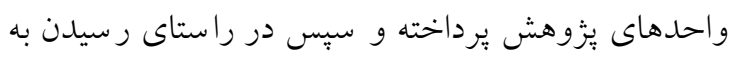

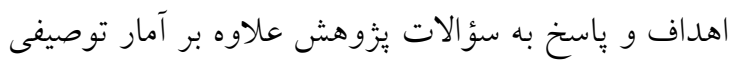

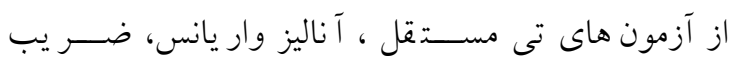
همب ستكى بيير سون و كرو سكال واليس مورد تحليل قرار

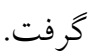

\section{يافتهها}

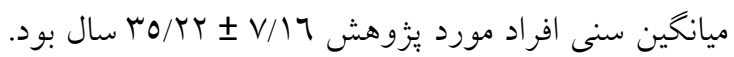

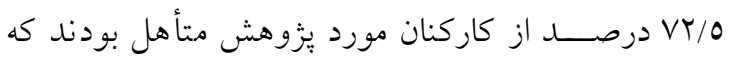
IV/T كارشناسى با ץ/ / ع درصد بيشترين فراوانى را در بين ساير سطوح تحصيلى داشت و رشته تحصيلى / •V در صد از

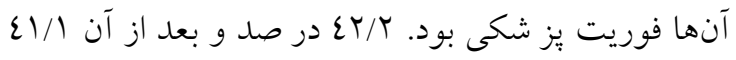
درصــ درآمد خود را به ترتيب در سـطح ناكافى و نسـبتاً

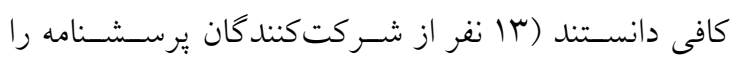

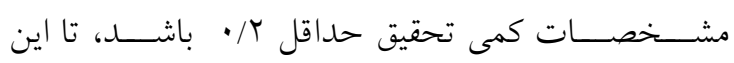

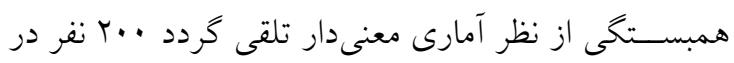

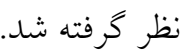
محقق پِس از كسـب مجوز انجام يزّوهش از كميته اخلاق

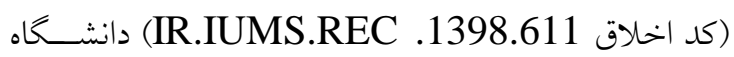
علوم يز شكى ايران، اخذ معرفى نامه از دانشكده ير ستارى

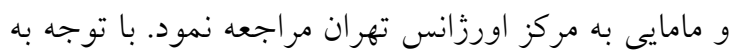
اين كه مركز اورزانس تهران به شش مركز (شمال، جنوب، شرق، غرب، مركز، اسلام شهر) تق سيم مى شود ابتدا به فهر

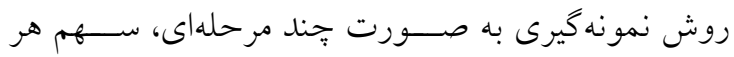

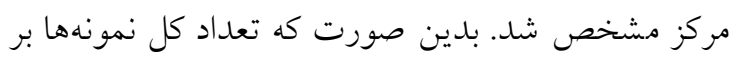
تعداد جامعه تقسيم و سبس ضرب در تعداد كاركنان هر

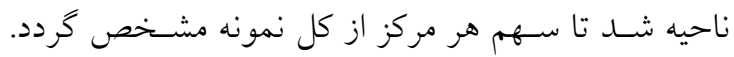

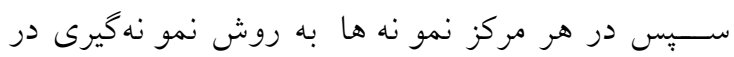
دسترس انتخاب شدند در اين مطالعه از فرم اطلاعات جمعيت شــناختى شـــامل

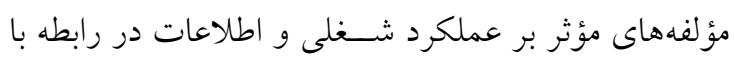

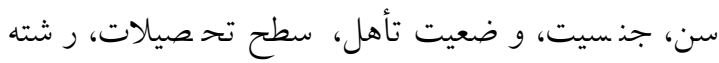

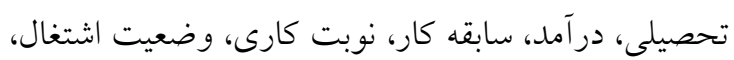

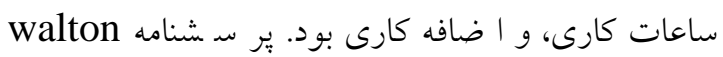
براى سنجش كيفيت زندگى (Quality of work life )

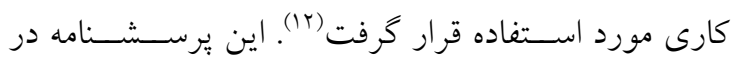

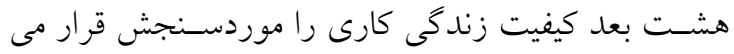

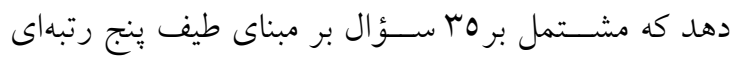

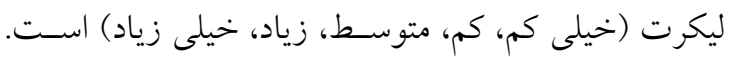

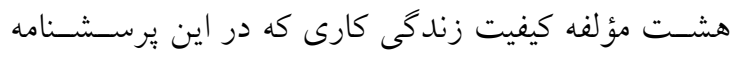
سنجيده مى شود شامل يرداخت منصفانه و كافى (سؤالات 1-ع)، محيط كارى ايمن و بهداشـتى (ســؤال ه تا •(1)،

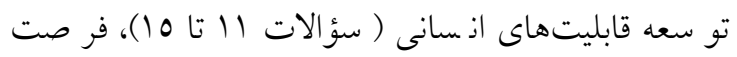

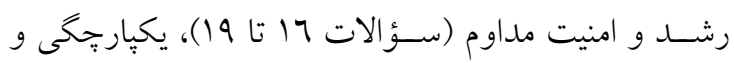

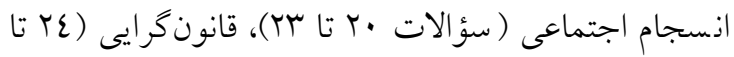
TY

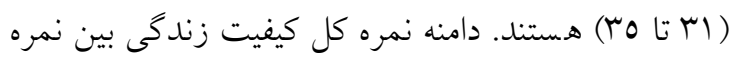

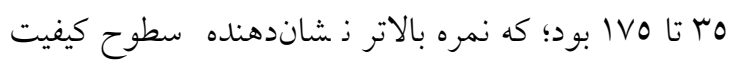


كارى خود را كمتر از •V ساعت اعلام كرده بودند و درصـــد اعلام كرده بودند اضــافهكارى مىكنند كه از اين

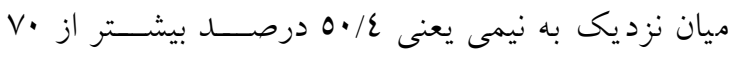
ساعت اضافهكارى در ماه داشتند. (جدول شماره ()
تكميل نكردند). ميانخين سابقه كار كاركنان مورد يزوهش  ساعته داشتند و استخدام شركتى با ب/ / در صد بيشترين فراوانى را در بين ساير سطوح داشت. T/N درصد ساعت

جدول شماره (: اطلاعات جمعيت شناختى (مشخصات فردى و شغلى) و همبستكى آنها با حمايت سازمانى ادراك شده و كيفيت زندتى

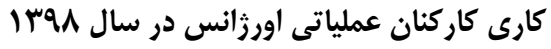

\begin{tabular}{|c|c|c|c|c|c|c|}
\hline \multicolumn{2}{|c|}{ حمايت سازمانى } & \multicolumn{3}{|c|}{ كيفيت زندگى كارى } & \multicolumn{2}{|c|}{ مشخصات فردى } \\
\hline نتيجه آزمون & ميانخين(انحراف معيار) & نتيجه آزمون & ميانخين(انحر افمعيار) & تعداد (درصد) & & \\
\hline $\mathrm{t}=1 / 091 \mathrm{df}=1 / \mathrm{r}$ & $r q / \varepsilon 7(\Sigma / \cdot V)$ & $\mathrm{t}=\cdot / \varepsilon \circ \varepsilon \mathrm{df}=\mathrm{A} \mathrm{r}$ & $9 \varepsilon / V \backslash(Y \backslash / 7 Y)$ & $0 \cdot(T V)$ & مجرد & وضعيت تأهل \\
\hline $\mathrm{p}=\cdot / / 1 \mu$ & TN/IT (O/TV) & $\mathrm{p}=\cdot / 70$ & $97 / \varepsilon(Y Y / V Y)$ & $\mid r \varepsilon(V Y / O)$ & متأهل & \\
\hline $\mathrm{F}=1 / .9 \mathrm{~V}$ & $r\rceil / V(0 / 0 \varepsilon)$ & $\mathrm{F}=\cdot / 1 \mathrm{TV}$ & $Q \Gamma / V \wedge(T r / K \varepsilon)$ & $\Gamma \mu(I V / T)$ & بدون فرزند & \\
\hline \multirow[t]{3}{*}{$\mathrm{p}=\cdot$ /ror } & 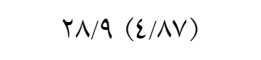 & $\mathrm{p}=\cdot / 919$ & $9 T / T V(Y \backslash / T)$ & or (rN/N) & 1 & تعداد فرزندان \\
\hline & TV/VA $(0 / 7)$ & & QV/AT (YT/TO) & $0 \cdot(r / T V)$ & r & \\
\hline & $r Q / r r(T / r)$ & & $90 / 17(Y N / I T)$ & $9(\mathrm{~T} / \mathrm{V})$ & r & \\
\hline $\mathrm{F}=\cdot / 0 \varepsilon \varepsilon$ & TN/OY $(T / / T)$ & $\mathrm{F}=r / \mathrm{u} / \mu$ & Nr/Vq (19/0V) & TO $(1 \% / 0)$ & دييلم & \\
\hline \multirow[t]{3}{*}{$\mathrm{p}=\cdot /$ /7or } & $Y N / \varepsilon O(0 / \cdot 7)$ & $\mathrm{p}=\cdot / \cdot 1 \mu$ & $90 / Y \wedge(Y Y / V \Lambda)$ & $79(\Gamma V / \Gamma)$ & كاردانى & سطح تحصيلات \\
\hline & TN/VV $(\varepsilon / T r)$ & & $99 / 29(Y Y / Y q)$ & $\Lambda \cdot(\varepsilon \Gamma / Y)$ & كارشناسى & \\
\hline & $r T / u(O / T V)$ & & $1 \cdot r / \cdot 7(17 / \vee 9)$ & $11(0 / 9)$ & كارشناسى ارشد & \\
\hline $\mathrm{F}=\cdot / / \wedge 0$ & TN/T $(0 / 17)$ & $F=r / 209$ & $9 \varepsilon / 1 \varepsilon(Y \cdot / 9)$ & $\operatorname{IrT}(V \cdot / 9)$ & فوريت بزشكى & \\
\hline \multirow[t]{3}{*}{$\mathrm{p}=\cdot / \vee\urcorner \varepsilon$} & $r q / r T$ (ร/qV) & $\mathrm{p}=\cdot / \cdot 70$ & $1 \cdot V / Y T(Y O / \cdot V)$ & ro $(1 \varepsilon / 0)$ & يرستارى & رشته تحصيلى \\
\hline & $r N / 17(r / V I)$ & & $1 . r / 77(T \circ / 7)$ & $7(r / 0)$ & 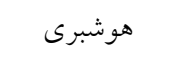 & \\
\hline & rN/Q (r/Ar) & & $9 T / 9(T r / 9 T)$ & $19(11)$ & امداد & \\
\hline \multirow[t]{4}{*}{$p=\cdot / 779$} & $r \cdot / \varepsilon r(\varepsilon / \cdot r)$ & $\mathrm{p}=\cdot / \Lambda \Lambda \mu$ & $11 r / 9(17 / \Lambda)$ & $V(\Gamma / \Lambda)$ & خوب & \\
\hline & $r q / r(T / 0 \varepsilon)$ & & $90(Y 1 / .0)$ & $r \varepsilon(\mid r)$ & كافى & در آمد \\
\hline & TN/TA $(0 / \cdot \varepsilon)$ & & $9 V / T(Y I / 2 r)$ & $V 7(\Sigma) / 1)$ & نسبتا كافى & \\
\hline & 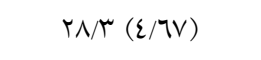 & & $q r / V \varepsilon(T r / \neg r)$ & $V \wedge(\Sigma Y / Y)$ & ن اكافى & \\
\hline$t=\cdot / 1 / \varepsilon d f=\backslash \wedge r$ & TN/OT ( $(/ V Q)$ & $t=\cdot / 997 \mathrm{df}=1 \wedge \mathrm{r}$ & $91 / 07(T \cdot / 97)$ & or $(Y q / T)$ & r I ساعت & \\
\hline $\mathrm{p}=\cdot / 9 \cdot 9$ & 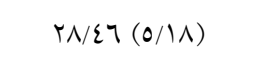 & $\mathrm{p}=\cdot / \mu r$ & QL/QT (YY/AV) & $|r|(V \cdot / \Lambda)$ & ع r r ساعت & نوبت كارى \\
\hline \multirow[t]{5}{*}{$\mathrm{p}=\cdot / V \varepsilon r$} & 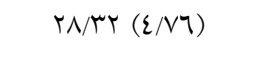 & $\mathrm{p}=\cdot / \cdot 10$ & $1 \cdot r / r q(T \cdot / 9 T)$ & $00(Y 9 / \mathrm{V})$ & رسمى & \\
\hline & 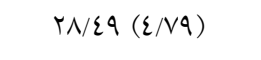 & & $\Lambda 9 / \mu Y(Y \backslash / \Sigma T)$ & $r\rceil(\mid \varepsilon / 1)$ & ي يمانى & وضعيت اشتغال \\
\hline & $r q / \cdot r(0 / \varepsilon V)$ & & 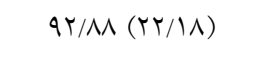 & $r 7(19 / 0)$ & قرار دادى & \\
\hline & $r\urcorner(\Sigma / 9 r)$ & & $V V / 71(10 / 07)$ & $7(r / T)$ & طرحى & \\
\hline & TN/ON $(0 / .9)$ & & $90 / A V(Y Y / \Lambda)$ & $7 r(T r / 0)$ & 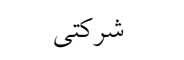 & \\
\hline $\mathrm{t}=1 / \mathrm{ro9} \mathrm{df}=1 \mathrm{rr}$ & TN/乏V $(\Sigma / 70)$ & $t=\cdot / 1 / r \mathrm{df}=1 \% 7$ & QV/VT (YI/乏V) & $90(T / 1)$ & Vمتر از Vم & ساعت كارى \\
\hline $\mathrm{p}=\cdot / / \mathrm{V} 7$ & $r q / \neg \Lambda(0 / T \Lambda)$ & $\mathrm{p}=\cdot / 91$ & $9 V / \pi T(19)$ & $\mid \varepsilon r(\Gamma \mid / T)$ & ل Vو بيشتر & \\
\hline $\mathrm{t}=\cdot N \mathrm{vI}$ & 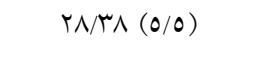 & $t=1 / 1 \mu \mathrm{V}$ & $9 \varepsilon / 0 Y(Y \cdot / 79)$ & $11 r(7 / / 1)$ & بله & اضافه كارى \\
\hline$d f=\mid \wedge r$ & YN/TV $(\varepsilon / \Gamma)$ & $d f=\backslash \wedge r$ & $Q \Lambda / \Gamma^{\prime} \circ(Y \varepsilon / \neg \Lambda)$ & $V T(r N / q)$ & 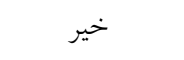 & \\
\hline $\mathrm{p}=\cdot / \mathrm{N} / 1$ & & $\mathrm{p}=\cdot / \mathrm{T} \diamond \mathrm{V}$ & & & & \\
\hline
\end{tabular}




\begin{tabular}{|c|c|c|c|c|}
\hline $\mathrm{F}=-. \cdot / .01$ & $\mathrm{r}=\cdot / \cdot 7$ & $\varepsilon \wedge(Y O / Q)$ & كمتر از •r & \\
\hline \multirow[t]{2}{*}{$\mathrm{p}=\cdot / \varepsilon \wedge \wedge$} & $\mathrm{p}=\cdot / \varepsilon / 0$ & $\wedge \varepsilon(\varepsilon 0 / \varepsilon)$ & $r \cdot-r q$ & سن، سال \\
\hline & & or $(Y \wedge / T)$ & •ع و بالاتر & \\
\hline $\mathrm{r}=-\cdot \cdot \cdot \cdot 1$ & $r=\cdot / \cdot \varepsilon r$ & $\varepsilon \varepsilon(Y \mu / \Lambda)$ & كمتر از 0 & سابقه كار، سال \\
\hline \multirow[t]{4}{*}{$\mathrm{p}=\cdot / \wedge 9 \vee$} & $\mathrm{p}=\cdot / 071$ & ru $(19 / 0)$ & $0-9$ & \\
\hline & & or $(Y N / T)$ & $1 \cdot-1 \varepsilon$ & \\
\hline & & $r \varepsilon(1 / / \varepsilon)$ & $10-19$ & \\
\hline & & $1 \wedge(9 / V)$ & r ب به بالا & \\
\hline
\end{tabular}

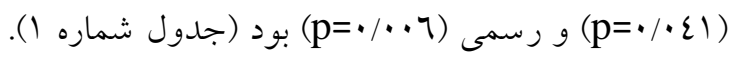
همجينين حمايت سازمانى ادراى شده نيز با هيج كدام از متغيرهاى فردى و شـــلى كاركنان مورد بزّوهش ارتباط معنى دار آمارى نداشت (جدول شماره (1).

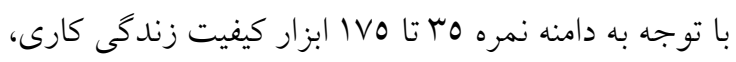
يافتهها نشان داد كيفيت زندكى كارى 10/2 درصد از كاركنان عملياتى مراكز اورزانس تهران در سطح متوسط بود. همجنين ملاحظه مىشود كه ميانخين نمره كيفيت

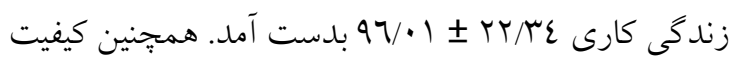

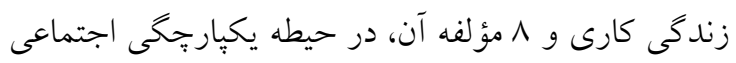

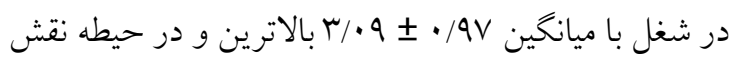
كار در زندگى با ميانخين AV/ • 土 نمره را در بين ساير حيطهها داشتند (جدول شماره Y).
همجنين نتايج بلد ست آملده در رابطه با همبستخى متغيرها با مشخصات جمعيت شناختى كاركنان عملياتى اورزانس نشـــان داد كه كيفيت ز ندكى كارى با تحصــيلات (1) ارتباط معنى دار آمارى داشـت. مقايسـه دو به له

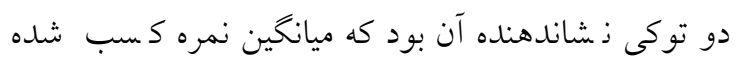
در كاركنان با تحصيلات در سطح ديبلم به طور معنىدارى

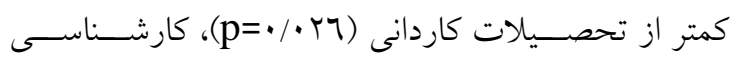

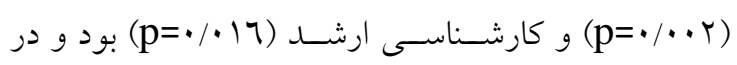
ساير موارد اين اختلاف معنى دار نبود. متغير ديخرى كه با

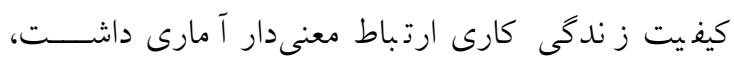

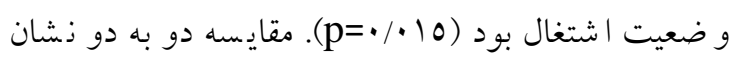
دهنده آن بود كه ميانخين نمره كسـب شـده در كاركنان با اســتختخدام طرحى به طور معنى دارى كمتر از شــركتى

جدول شماره ז: شاخصهاى عددى حيطههاى كيفيت زندكى كارى كاركنان عملياتى مركز اورزانس تهران در سال يوسا

\begin{tabular}{|c|c|c|c|c|c|c|c|c|}
\hline \multicolumn{4}{|c|}{ مبناى ا تا ه } & \multirow{2}{*}{ انحر اف } & \multirow[t]{2}{*}{ 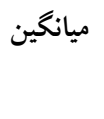 } & \multirow[t]{2}{*}{ بيشينه } & \multirow[t]{2}{*}{ كمينه } & \multirow[t]{2}{*}{ حيطههاى كيفيت زندگى كارى } \\
\hline انحراف معيار & ميانگين & بيشينه & كمينه & & & & & \\
\hline - No & $r / 71$ & $\varepsilon / 0$ & $1 / \mathrm{SO}_{0}$ & $r / \cdot 1$ & $1 \cdot / \varepsilon V$ & 11 & 0 & حقوق مناسب \\
\hline$\cdot / v \varepsilon$ & $T / V I$ & 0 & $1 / 1 \mathrm{~V}$ & $\varepsilon / \varepsilon r$ & $17 / T 0$ & r. & $\checkmark$ & شرايط كارى \\
\hline$\cdot N r$ & r/vq & $\varepsilon / 7$ & 1 & $r / 70$ & $14 / 91$ & r & 0 & بكارگيرى قابليتهاى فرد در كار \\
\hline$\cdot / N V$ & $r / N r$ & 0 & 1 & $r / .9$ & $1 . / 90$ & $r \cdot$ & $\varepsilon$ & فرصتهاى كارى \\
\hline$\cdot / 9 V$ & $r / .9$ & 0 & 1 & $r / \Lambda \Lambda$ & $I T / R V$ & r. & $\varepsilon$ & يكيارٍخى اجتماعى در شغل \\
\hline$\cdot / 9 r$ & T/TV & 0 & 1 & $r / 79$ & $1 \cdot / V$ & r. & $\varepsilon$ & قانون كرايى در كار \\
\hline$\cdot / \mathrm{AV}$ & T/MO & 0 & 1 & $r / 71$ & $\mathrm{~V} / \cdot \mathrm{V}$ & 10 & $r$ & نقش كار در زندكى \\
\hline$\cdot / \mathrm{AV}$ & r/A & $\varepsilon / \wedge$ & 1 & $\varepsilon / r_{0}$ & $1 \varepsilon / 10$ & $T \varepsilon$ & 0 & وجهه اجتماعى و اهميت كارى \\
\hline$\cdot / 0 r$ & $r / 91$ & $\varepsilon / Y\urcorner$ & $1 / 29$ & TT/R & $97 / \cdot 1$ & l々^ & $\varepsilon r$ & كيفيت زندكى كارى (كل) \\
\hline
\end{tabular}


بحث و نتيجه تيرى

اين يزوهش با هدف تعيين حمايت سازماني ادراى شيرى شده و كيفيت زندگى كارى كاركنان عملياتى مركز اورزانس

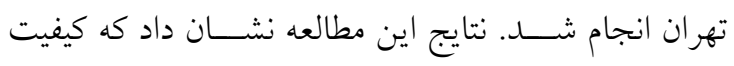

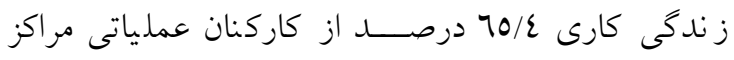

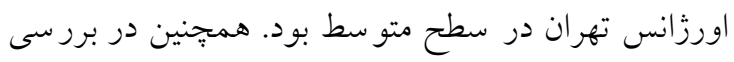

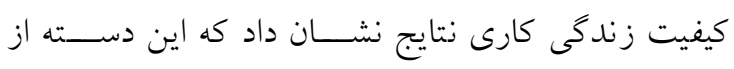

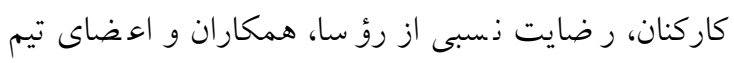

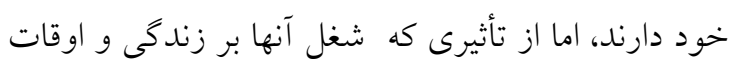
فراغت آنها كذاشته است ناراضى اند. در مطالعه نخهدارى تاني

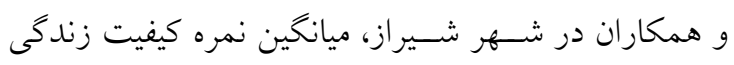

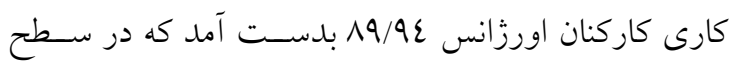
متو سط ا ست (ع). همجنين مطالعه شفيع يور و همكاران

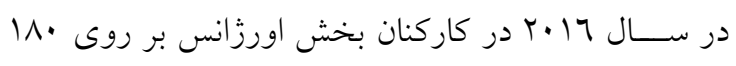
نفر از كاركنان بخش اورزانس بيمارســتان هاى اســتان

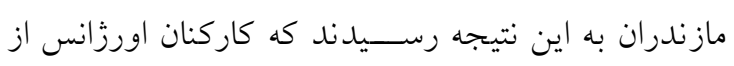

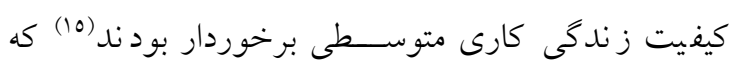

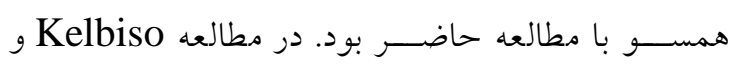

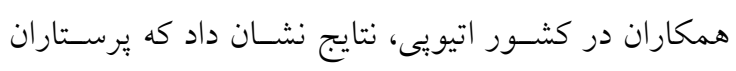

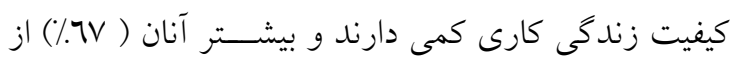

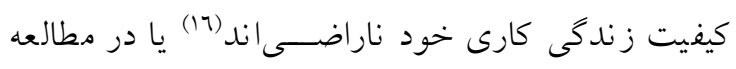

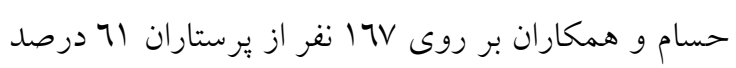

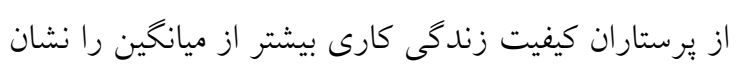

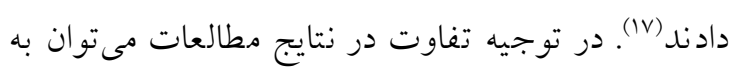
نقش عوامل مختلف فردى، اجتماعى، فرهنكى و همجنين سازمانهاى كارى مختلف اشاره كرد.

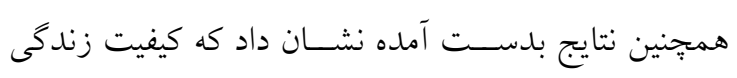

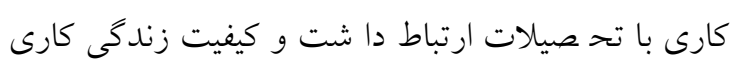

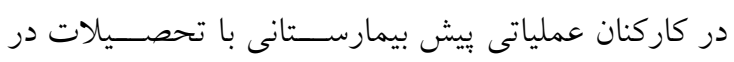

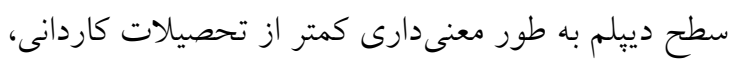

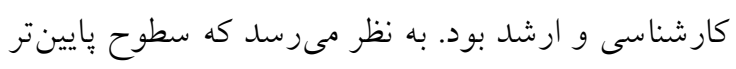
كيفيت زندگى كارى در كاركنان با سطح تحصيلات دييلم

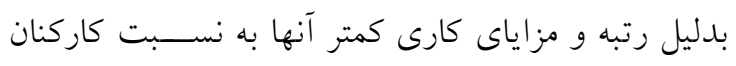
داراى تحصيلات كار شنا سى و كار شنا سى ار شد با شد.
براسـاس نتايج مطالعه حاضـر، حمايت سـازمانى NT/Y در صد از واحدهاى مورد يُزوهش در سطح متو سط بود.

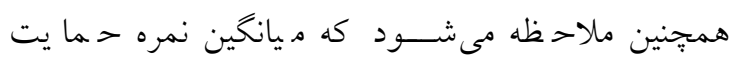

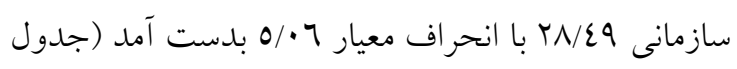

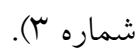

جدول شماره سّ: توزيع فراوانى ميزان حمايت سازمانى ادراى

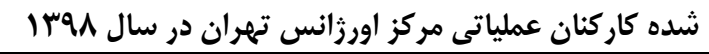

\begin{tabular}{|c|c|c|}
\hline درصد & فراوانى & حمايت سازمانى \\
\hline $17 / r$ & r. & ضعيف (^ تا ع r) \\
\hline$\Lambda T / r$ & lor & متوسط (•ع- \\
\hline $1 / 7$ & r & بسيارخوب (•ـ-07) \\
\hline 1.. & 110 & كل \\
\hline \multicolumn{2}{|c|}{$\Upsilon N / \Sigma 9 \pm 0 / \cdot 7$} & انحراف معيار \ميانخين \\
\hline \multicolumn{2}{|c|}{$10-\varepsilon r$} & بيشينه - كمينه \\
\hline
\end{tabular}

همجنِين بر اساس نتايج بدست آمده، كيفيت زندگى كارى

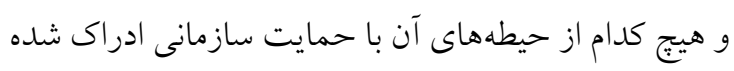

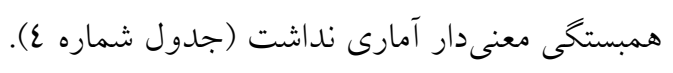

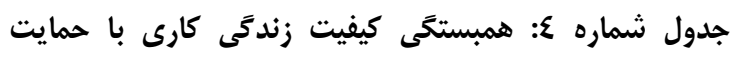

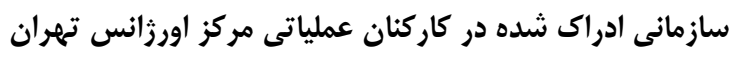

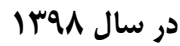

\begin{tabular}{|c|c|}
\hline حمايت سازمانى ادراكشده & كيفيت زندگى كارى و حيطه \\
\hline $\mathrm{r}=\cdot / \mathrm{r} \quad \mathrm{P}=\cdot / 1 \cdot r$ & حقوق مناسب \\
\hline $\mathrm{r}=\cdot / \wedge 1 \quad \mathrm{P}=\cdot / \mathrm{rV} \mid$ & شرايط كارى \\
\hline$r=\cdot / \cdot r 1$ & بكار گيرى قابليت هاى فرد در \\
\hline $\mathrm{P}=\cdot /$ / $\vee 0$ & كار \\
\hline $\mathrm{r}=\cdot / N \mu \quad \mathrm{P}=\cdot / \mu r \varepsilon$ & فرصت هاى كارى \\
\hline $\mathrm{r}=-\cdot / \cdot \varepsilon \quad \mathrm{P}=\cdot / 907$ & يكِارجخى اجتماعى در شغل \\
\hline $\begin{array}{r}r=\cdot / .97 \\
P=\cdot / 194\end{array}$ & قانون گرايى در كار \\
\hline $\begin{array}{l}\mathrm{r}=\cdot / \cdot / r \\
\mathrm{P}=\cdot / \lambda \vee \varepsilon\end{array}$ & نقش كار در زندگى \\
\hline $\mathrm{r}=-\cdot / / \quad \mathrm{P}=\cdot / \wedge \wedge 9$ & وجهه اجتماعى و اهميت كارى \\
\hline $\mathrm{r}=. / .01 \quad \mathrm{P}=\cdot / \varepsilon \wedge \vee$ & كيفيت زندگى كارى \\
\hline
\end{tabular}




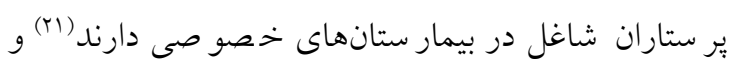

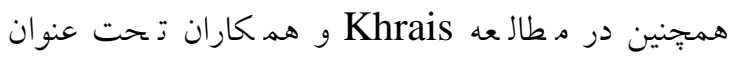

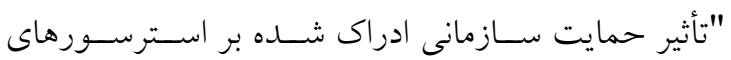

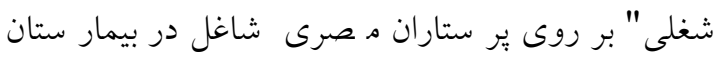

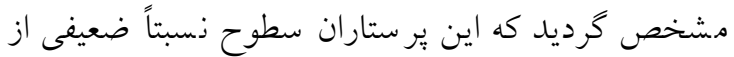

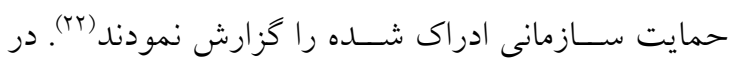
توجيه مطالعات ناهمسو با اين يزوهش، محقق مىتواند به

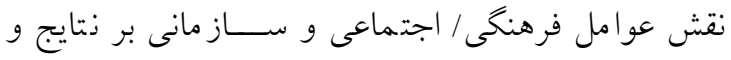

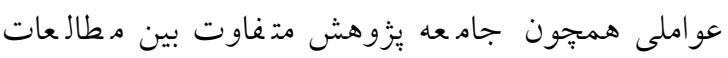

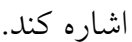

بر اساس نتايج اين مطالعه، حمايت سازمانى ادراك شده با

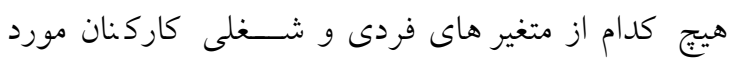

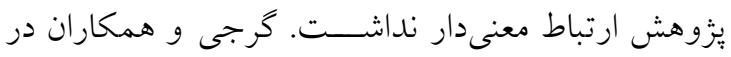

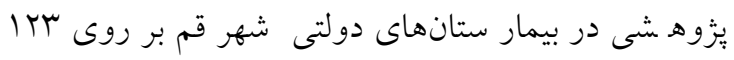

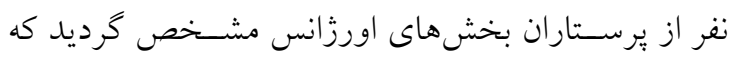

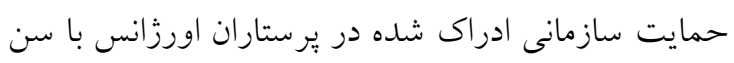

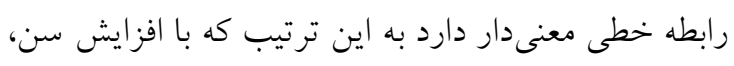

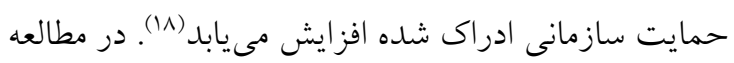

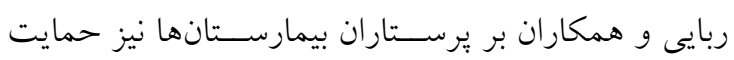

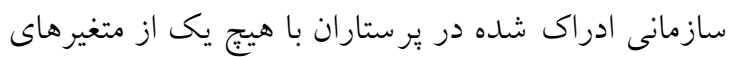

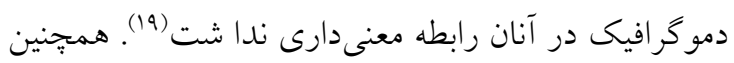

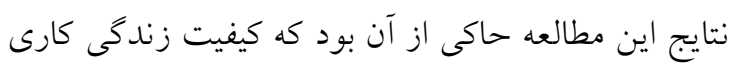

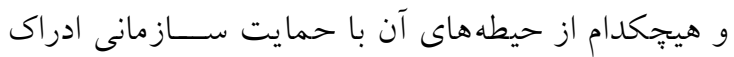

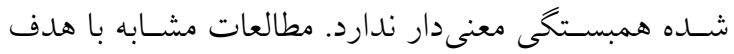

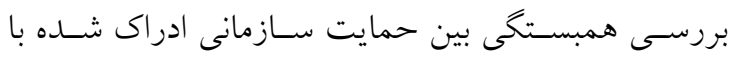
كيفيت زندگى كارى كاركنان يافت نشد.

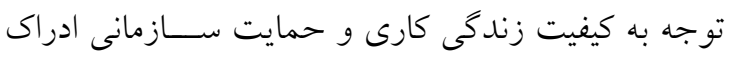
شـــه در قشـــ كاركنان اورزانس ييش بيمارسـتانى حائز اهميت بوده زيرا مىتواند جوانب مختلف شــلى، فردى، زندگى و اجتماعى آنها را تحت تأثير قرار دهد. بنابر اين با تو جه به اهميت اين متغير، تو جه دوخهندان به آن ضـرورى اسـت. همجنين با توجه به اينكه درى اكثريت كاركنان اورزانس بيش بيمار ستانى از حمايت سازمانى در بانيان

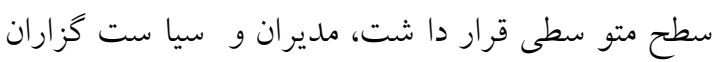

همجنين بر ا ساس نتايج، كيفيت زندكى كارى در كاركنان

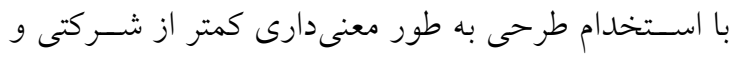
رسمى بود. مطالعه حاضر تا حدوى با مطالعات انجام شده

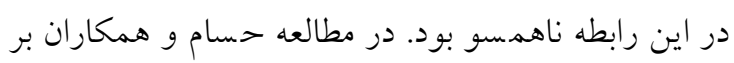
روى IVV انفر از ير ستاران نتايج مشخص نمود كه كيفيت

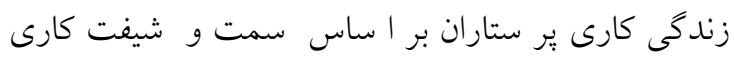

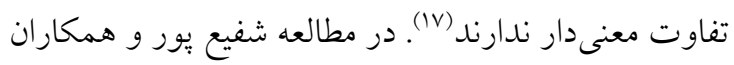

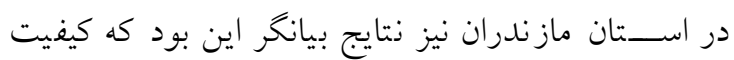

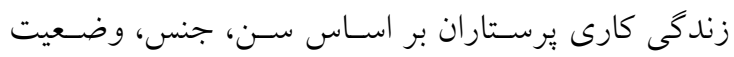

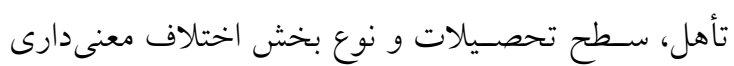
وجود ندارد، اما كيفيت زندكى كارى با متغير هايى مانند

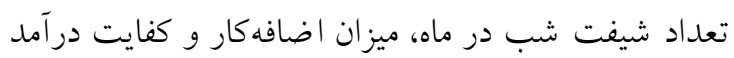

$$
\text { رابطه معنى دارى دارد (10). }
$$

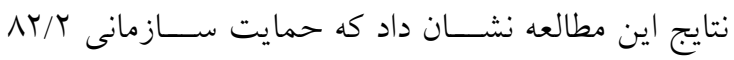

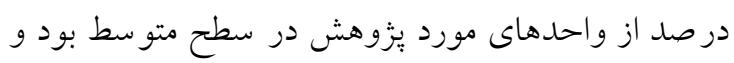

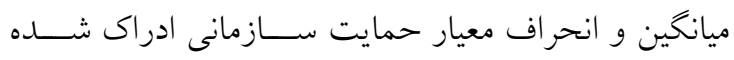

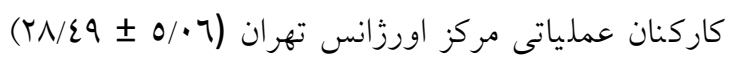

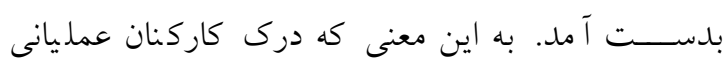
اورزانس تهران از حمايت سازمانى در حد متوسطى است.

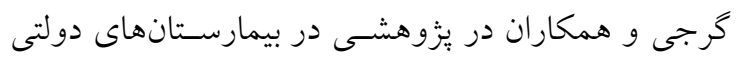

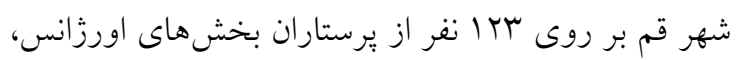

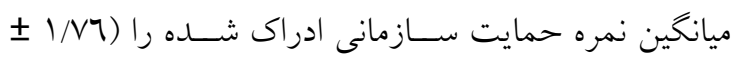

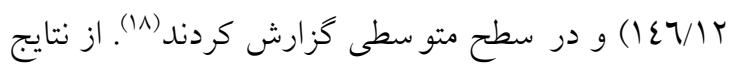
غير هم سو مىتوان به يزوه ششى تو سط ربايى و همكاران

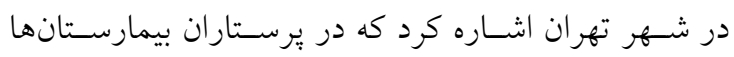
حمايت سازمانى ادراك شده در سطح بايينى قرار دارد (19). در مطالعه سـبك رو و همكاران در بيمارستانهاى شهـر

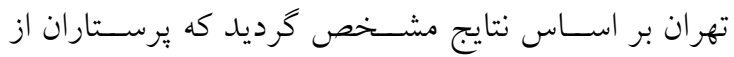

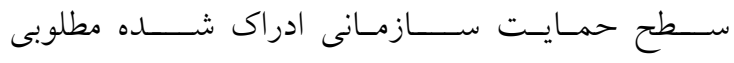

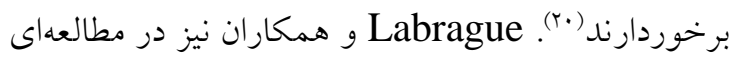

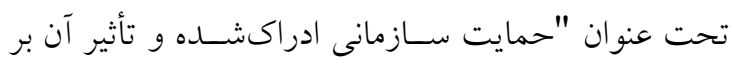
نتايج شغلى ير ستاران" در ك شور فيلييين انجام دادند كه

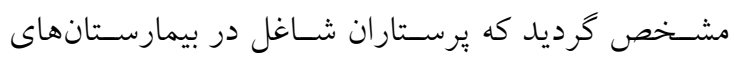

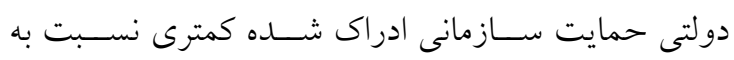


راهبردى و جالشهاى سـازمانى كمك كند. به خصـوص

در شــرايط همه كيرى كوو يد-19 كه اهميت تو جه به كيفيت زندكى كارى و حمايت سـازمانى ادراك شــده دو جندان مىشــود. همجينين با توجه به اينكه اين مطالعه در مركز اورزانس تهران انجام شد بيششنهاد مى شود در ساير مراكز در شهرهاى ديخر نيز انجام شود و بيشنهاد مى شود كه يزّوهشهاى مشـابه در سـاير حرفههاى بالينى انجام و نتايج آن مقايسه شود.

تعارض منافع:هيج گونه تعارض منافع از سوى نويسندگان كزارش نشده است.

\section{تقلدير و تشكر}

نويسنده بر خود لازم مىداند تا مراتب قدردانى و تشكر را از بايخاههاى اورزانس شهرى، مسؤلان و كاركنان آنان و اساتيد دانشخاه بابت همكارى اعلام نمايند. اين مقاله حاصل پِايان نامه كارشناسى ارشد در رشته پِرستارى اورزانس در دانشخاه علوم يزشكى ايران است.
مربو طه مىتوانـند با تو جه بـه آن تلاش هاى ســــاز مانى بيشـترى در جهت ارتقاء بهينهسـازى حمايت سـازمانى انجام دهند. زيرا درك كاركنان اورزانس بيش بيمارسـتانى از مورد حمايت واقع شــدن مىتواند منجر به بهبود يِيامد هاى شـغلى و سـازمانى گردد. و بايد حمايت سـازمان از كاركنان به نحوى باشد كه كاركنان خود را مديون سازمان بدانند. همجنين تو جه به كيفيت زندكى كارى از عوامل عمده در رضـايتمندى كاركنان، افزايش اثربخشـى آنان و تو سعه سازمان بشمار مىرود. با توجه به سطوح متو سط حمايت سـازمانى ادراك شــده و كيفيت زندگى كارى در كاركنان اورزانس بيش بيمارســتانى، اين يافتهها مىتواند مورد توجه مديران و مســئولان درمانى و سـياسـتخذاران مربوطه قرار بخيرد تا با اتخاذ رويكردهاى منا سب و بهبود شـرايط كارى/ســازمانى در جهت توجه به اين دو مؤلفه كوشـش ورزند و قدمهاى بيشـترى را در جهت تعديل و بهبود كيفيت زندكى كارى و حمايت سازمانى ادراك شده و در افزايش رضــــايت كارى در كاركنان اورزانس بيش بيمارسـتانى بردارند و آنان را در جهت تدوين برنامههاى

\section{References}

1. Hamidi Y, Vakilian M, Roshanaei G, Makvandi Z, Atogara M, Bayat F. Correlation of nurses' quality of working life and job satisfaction in teaching hospitals of Hamadan University of Medical Sciences. Avicenna Journal of Nursing and Midwifery Care. 2019;27(1):64-72. [Persian]

2. Luchette FA, Yelon JA, editors. Geriatric trauma and critical care. Springer; 2017 Jul 30. p:239-46.

3. Forouzandeh N, Aslani Y, Mehralian H, Deris F. The association between academic stress and quality of life in students. Journal of Shahrekord Uuniversity of Medical Sciences. 2016;18(3):1-7. [Persian]

4. Srivastava S, Kanpur R. A study on quality of work life: key elements \& It's Implications. IOSR J Busin Manag. 2014;16(3):54-9.

5. Rastogi M, Rangnekar S, Rastogi R. Enhancing quality of work life in India: the role of workplace flexibility. Industrial and commercial Training. 2018 Jun 4.

6. Circenis K, Millere I, Deklava L. Measuring the professional quality of life among Latvian nurses. Procedia Social Behav Sci. 2013;84:1625-9.

7. Dargahi H, Gharib MI, Goudarzi M. Quality of work life in nursing employees of Tehran University of Medical Sciences hospitals. J Hayat. 2007;13(2):13-21. [Persian]

8. Seyedoshohadaee, Oghli H. quality of work life. tehran: maahtab; 2015. 112 p. [Persian]

9. Eisenberger R, Huntington R, Hutchison S, Sowa D. Perceived organizational support. J Appl psychol. 1986;71(3):500.

10. Afjei SA, Yazdanshenas M, Zargaran Khouzani F. Explaining the Pattern for Perceived Organizational Support Impact. Management Studies in Development and Evolution. 2019;28(91):87-118. [Persian] 
11. Sarvestani. Relationship between quality of work life, perceived organizational support and work performance of Sarvestan Martyrs Hospital staff and city health houses: Islamic Azad University, Marvdasht Branch; 2011. [Persian]

12. Cherns AB, Davis LE. Goal for enhancing the quality of working life. The quality of working life. 1975;1:55-62.

13. Eisenberger R, Cummings J, Armeli S, Lynch P. Perceived organizational support, discretionary treatment, and job satisfaction. J Appl Psychol. 1997;82(5):812.

14. Negahdari A, Jadid-Milani M, Alemohammad SN, Pishgooei SA. The relationship between job stress and quality of work life among prehospital emergency personnel in Shiraz, 2017. Iranian Journal of Nursing Research. 2019;13(6):48-53. [Persian]

15. Shafipour V, Momeni B, Yazdani Charati J, Esmaeili R. Quality of working life and its related factors in critical care unit nurses. J Mazandaran Univ Med Sci. 2016;26(142):117-26. [Persian]

16. Kelbiso L, Belay A, Woldie M. Determinants of quality of work life among nurses working in Hawassa town public health facilities, South Ethiopia: a cross-sectional study. Nursing Research and Practice. 2017;2017:5181676.

17. Hesam M, Asayesh H, Roohi G, Shariati A, Nasiry H. Assessing the relationship between nurses' quality of work life and their intention to leave the nursing profession. Quarterly Journal of Nursing Management. 2012;1(3):28-36. [Persian]

18. Gorji HA, Etemadi M, Hoseini F. Perceived organizational support and job involvement in the Iranian health care system: a case study of emergency room nurses in general hospitals. Journal of education and health promotion. 2014;3:58. [Persian]

19. Robaee N, Atashzadeh-Shoorideh F, Ashktorab T, Baghestani A, Barkhordari-Sharifabad M. Perceived organizational support and moral distress among nurses. BMC nursing. 2018;17(1):1-7.

20. Sabokroo M, kalhorian r, Kamjoo Z, Taleghani G. Work-family Conflict: The Role of Organizational Supportive Perception in Turnover Intention (Case study of nurses of Tehran's hospitals. Journal of Public Administration. 2011;3(6):111-236. [Persian]

21. Labrague LJ, McEnroe Petitte DM, Leocadio MC, Van Bogaert P, Tsaras K. Perceptions of organizational support and its impact on nurses' job outcomes. InNursing forum. 2018 ;53(3): 33947.

22. Khrais H, Higazee MZ, Khalil M, Wahab SD. Impact of organizational support on nursing job stressors: a comparative study. Health Science Journal. 2018;12(4):1-6. 